\title{
COMMENTARY
}

\section{Wicked Problems in Pharmacy Education}

\author{
Kathryn J Smith, PharmD \\ The University of Oklahoma, College of Pharmacy, Oklahoma City, Oklahoma \\ Corresponding Author: Kathryn J Smith, The University of Oklahoma, College of Pharmacy, 1110 N Stonewall Ave \\ CPB 229, Oklahoma City, OK 73117.Tel: 773-368-9711. Email: kathryn-j-smith@ ouhsc.edu
}

Submitted November 30, 2020; accepted March 10, 2021; ePublished March 2021

Wicked problems are unstructured, cross-cutting, and relentless. While problem-solving is an expected outcome of pharmacy education programs, are we, as pharmacy educators, acknowledging the wicked problems we have in the Academy? This commentary will provide examples of wicked problems in pharmacy practice and education and provide suggestions for engaging with wicked problems in an effort to solve them. Pharmacy educators must hold a Summit on Wicked Problems in Pharmacy Education in order to address the complex problems we are currently facing in order to shape the profession for the future.

Keywords: wicked problems, complexity, problem-solving, pharmacy education

The profession of pharmacy is teeming with complex or "wicked" problems. Originally described in the field of governmental, social and policy planning, wicked problems have also been identified in education, public health, and environmental science. ${ }^{1-4}$ Tame problems are easy to define and have a straightforward, technical solution which can be implemented and lead to a predictable result. Wicked problems are situations where the parameters of the problem and the means available for solving the problem are constantly changing. ${ }^{1}$ While every wicked problem is essentially unique, all wicked problems are unstructured. ${ }^{5}$ Problem-definition is challenging if not impossible for wicked problems. Every question asking for additional information about the original question depends upon the understanding of the problem. ${ }^{6}$ Wicked problems are also cross-cutting. Stakeholders with different perspectives and desired outcomes have a high degree of interdependency, which leads to a high potential for conflict when attempting to solve wicked problems. ${ }^{5}$ Any discrepancies in wicked problems can be explained in multiple ways. How you explain discrepancies influences how you will attempt to solve the problem. Wicked problems are relentless. There are no criteria to determine if all possible solutions have been identified, nor it is easy to test if an attempted solution to the problem has fully solved it. Attempts to solve the problem have waves of consequences which may yield unexpected repercussions. ${ }^{5}$ Even consistent implementation of a model for resolution will yield different results for different institutions.

You can certainly think of a wicked problem or two you have observed as a pharmacist in practice. Clinical problems faced by our patients are often wicked and complex. Consider the patient who cannot read but needs to manage a medication regimen for diabetes which includes two different insulins, three oral medications, testing blood sugar multiple times a day and counting carbohydrates. Normal solutions for helping this patient manage the complexity of the regimen will not work. The pharmacist caring for this patient needs to take into consideration the risks of low or high blood sugar, the patient's support system at home, the patient's willingness to participate in their own care, the costs of medication and food and the long-term goals of the patient to determine a reasonable A1C goal. Different pharmacists will have different methods of prioritizing problems identified for this patient and different solutions to implement. There is likely not one right approach to managing this patient's diabetes, but multiple better or worse approaches. While a pharmacist may memorize the recommended A1C goal, it is easy to get overwhelmed when determining how adjust medication to assist a real patient reach their A1C goal. Not only are pharmacists wrestling with patient specific clinical issues, but systemic, profession-wide wicked problems also exist. Pharmacist-patient communication, interprofessional communication, health care costs, patient access to care, and the opioid epidemic are each rooted in one or more wicked questions. ${ }^{7-9}$

Pharmacy education has its own set of wicked problems. ${ }^{10-12}$ The increase in the number of pharmacy schools coupled with a declining number of applicants and lower enrollment means schools are not filling available spots in Doctorate of Pharmacy programs. Faculty must consider daily how to balance content knowledge with application of that content in a clinical setting. Deans and other administrators are seeking new business models to fund the work of their institutions. Upon graduation, new pharmacists face limited residency or employment opportunities. 
This leads to two questions: (1) how can pharmacy educators prepare future pharmacists to manage wicked problems they will inevitably face once in practice and (2) how can pharmacy educators effectively approach wicked problems facing in the Academy? Most pharmacists prefer working with things we can measure or count, or an algorithm we can follow. But wrestling with unstructured, cross-cutting, and relentless issues requires new methods of critical thinking in the classroom, in practice, and in the Academy. While problem-solving is a desired outcome of pharmacy education programs, there is little consensus about how to teach or develop problem-solving skills in our students. ${ }^{13}$

In his 2018 book "Creating Wicked Students", Paul Hanstedt asserts "if we want to create wicked students who can respond thoughtfully to complex problems, the best way to do that is to give them wicked problems over and over and over again and ask them to solve them." ${ }^{\prime 6}$ How do we adjust what we're doing in our classrooms and experiential sites to develop the problem-solving skills future pharmacists need to make decisions in a complex world? Handstedt offers three ideas applicable to pharmacy students, practicing pharmacists, and pharmacy educators. First, begin your course or rotation with a Beautiful Problem - the kind of question that engages your curiosity and intellect and keeps you awake at night. ${ }^{14}$ Provide an example of a complex patient you've cared for in practice, and how you identified drug therapy problems the patient was experiencing. Second, provide a framework with which to approach complex problems. One of the best frameworks available to pharmacists is the Pharmacists' Patient Care Process (PPCP). ${ }^{15}$ Much has been written about how to incorporate the PPCP throughout pharmacy school. ${ }^{16-19}$ Using a framework such as the PPCP does not mean wicked problems suddenly become solvable, but it can provide a step-wise process to organize and make sense of the information students and pharmacists have or need about their patients. Third, students need pharmacists and faculty who model passion, vulnerability and failure. Provide examples of how you have wrestled with the content during residency or in practice, or where you have failed to apply the content correctly. ${ }^{20}$ Discuss complex cases with multiple solutions and sit in the discomfort of not knowing exactly how to solve the drug therapy problems identified. This vulnerability can build trust between you and your students and lead to greater self-acceptance as students learn to think critically themselves. ${ }^{21}$ As you demonstrate problem-solving with your patients, your students will grow in their comfort with complexity and uncertainty. After all, we need pharmacists to be able to apply not just the content covered during their education but also the content that has not yet been invented, thought of, or discovered. ${ }^{6}$

In addition to clinical problem-solving, pharmacists must also engage in conversations about complex problems facing the profession as a whole. Canadian pharmacists dedicated themselves to problem-solving when they gathered for a National Summit on Wicked Problems in Community Pharmacy in 2018. ${ }^{9}$ The goal of the summit was to developed a unified approach to solving practice problems between practitioners, employers, regulators and other stakeholders. A number of changes needed within the pharmacy profession were identified including increased pharmacist confidence in applying and practicing their full scope and greater synergy between business models and delivery of patient care. During the summit, participants were introduced to several theoretical models of behavior change which they applied to the wicked problem of pharmacist communication with patients and other health care providers. These models provided a framework for approaching the wicked problems identified. Suggested interventions included involving patients in the care process and being intentional about where pharmacist-patient communication occurs in the community practice settings. ${ }^{9}$ Neither of these solutions could improve pharmacist communication with patients and other providers in every situation, but they were attempts to solve this complex problem. The conversation among stakeholders prompted thoughtful dialogue and increased appreciation for the complexity of the issues facing pharmacists in community practice in Canada. ${ }^{9}$

It is time for intentional engagement with the complex problems facing the Academy; it is time for a Summit on Wicked Problems in Pharmacy Education. Pharmacy educators must be willing to have uncomfortable conversations about the present if we are going to shape the future of the profession. The act of having the difficult conversation can promote innovation and creativity in the face of complex problems. As Handstedt suggested, we could start by painting a picture of wicked problems facing pharmacy education, the problems that keep us up at night. We would need a framework from which to approach these problems, perhaps something similar to the behavioral change models used by the Canadians in their Summit, or a design thinking problem-solving process. ${ }^{9,22}$ We could seek solutions to wicked problems which could be implement across institutions with specific goals and clear methods of assessing success. A summit such as this would require vulnerability on the part of pharmacy educators but would demonstrate a commitment to improving pharmacy education for all stakeholders- faculty, staff, current and future students, interprofessional collaborators and, of course, patients.

As demonstrated by the Canadian pharmacists Summit on Wicked Problems in Community Pharmacy, difficult conversations can lead to productive solutions to complex and interconnected problems. ${ }^{9}$ We will not be able to transform pharmacy education and practice by doing things the way we have always done them. The profession needs educators and 
clinicians who will lead by example, and risk starting the conversation about complex problems in pharmacy education even when we cannot predict everything the future holds.

\section{ACKNOWLEDGMENTS}

The author would like to thank Dr. Melissa Medina for her assistance in reviewing this commentary prior to submission.

\section{REFERENCES}

1. Rittel, HWJ, Webber MM. Dilemmas in a General Theory of Planning. Policy Sciences.1973;4:155-169.

2. Wass V. 'A wicked problem': does medical education produce better doctors?. Educ Prim Care. 2019;30(6):329-330. doi:10.1080/14739879.2019.1692312

3. Came H, Griffith D. Tackling racism as a "wicked" public health problem: enabling allies in anti-racism praxis. Soc Sci Med. 2018;199:181-188. doi:10.1016/j.socscimed.2017.03.028

4. DeFries R, Nagendra H. Ecosystem management as a wicked problem. Science. 2017;356(6335):265-270. doi:10.1126/science.aal1950

5. Weber EP, and Khademian AM. Wicked Problems, Knowledge Challenges, and Collaborative Capacity Builders in Network Settings. Public Administration Review. 2008;68(2):334-349. doi:10.1111/j.1540-6210.2007.00866.x

6. Handstedt P. Creating Wicked Students: Designing Courses for a Complex World. Sterling, VA: Stylus Publishing LLC; 2018.

7. Rozario, D. Burnout, resilience and moral injury: How the wicked problems of health care defy solutions, yet require innovative strategies in the modern era. Can J Surg. 2019;62(4):E6-E8.

8. Lee JC. The opioid crisis is a wicked problem. Am J Addict. 2018;27(1):51. doi:10.1111/ajad.12662

9. Bishop A, Zwicker B. Report from the 2018 National Summit on Wicked Problems in Community Pharmacy. Can Pharm J (Ott). 2019 Apr 16;152(3):158-159. doi: 10.1177/1715163519840374.

10. Brown DL. A looming joblessness crisis for new pharmacy graduates and the implications it holds for the academy. Am J Pharm Educ. 2013;77(5): Article 90. https://doi.org/10.5688/ajpe77590.

11. Pavuluri N, Aparasu RR, Boje KMK, et al. Consideration of aggressive and strategic approaches to address declining enrollment in US pharmacy schools. Am J Pharm Educ. 2019;83(6): Article 6959. https://doi.org/10.5688/ajpe6959.

12. Brown D. From shortage to surplus: the hazards of uncontrolled academic growth. Am J Pharm Educ. 2020;84(10): Article 8136. https://doi.org/10.5688/aj7410185.

13. Accreditation Council for Pharmacy Education. Accreditation standards and guidelines for the professional program in pharmacy leading to the doctor of pharmacy degree. Standards 2016. https://www.acpeaccredit.org/pdf/Standards2016FINAL.pdf. Accessed March 10, 2020.

14. Hanstedt, P. Five Tips for Getting a Good Start on the Semester (and Maybe Even Enjoying Ourselves a Little) https://community.acue.org/blog/five-tips-for-getting-a-good-start-on-the-semester-and-maybe-even-enjoyingourselves-a-little/ Accessed November 30, 2020.

15. Joint Commission of Pharmacy Practitioners. Pharmacists' Patient Care Process. 2014. https://jcpp.net/wpcontent/uploads/2016/03/PatientCareProcess-with-supporting-organizations.pdf Accessed March 10, 2021.

16. Alsharif NZ, Faulkner MA. Implementation of the Pharmacists' Patient Care Process in a Medicinal Chemistry Course. Am J Pharm Educ.. Feb 2020, 84 (2) 7556; DOI: 10.5688/ajpe7556

17. Gonyeau MJ, Divall M, Conley MP, Lancaster J. Integration of the Pharmacists' Patient Care Process (PCPP) into a comprehensive disease management course series. Am J Pharm Educ. 2018;82(6): Article 6311; DOI: https://doi.org/10.5688/ajpe6311

18. Rivkin A. Thinking clinically from the beginning: early introduction of the Pharmacists' Patient Care Process. Am J Pharm Educ. 2016;80(10): Article 164; DOI: https://doi.org/10.5688/ajpe8010164

19. Smith KJ. Incorporating the Pharmacists' Patient Care Process into an Interprofessional Second Year Capstone. Currents in Pharmacy Teaching and Learning. 2020;12(1):41-48. https://doi.org/10.1016/j.cptl.2019.10.006

20. Molloy E, Bearman M. Embracing the tension between vulnerability and credibility: 'intellectual candour' in health professions education. Med Educ. 2019;53(1):32-41. doi:10.1111/medu.13649

21. Bloom TJ. The Importance of Vulnerability in Pharmacy Educators. Am J Pharm Educ. 2020;84(7):ajpe7939. doi:10.5688/ajpe7939

22. Wolcott MD, McLaughlin JE. Promoting Creative Problem-Solving in Schools of Pharmacy With the Use of Design Thinking. Am J Pharm Educ. 2020;84(10):ajpe8065. doi:10.5688/ajpe8065 